\title{
Memória dos bárbaros no jardim dos civilizados: corpo e vídeo no pensamento coreografico de Montalvo-Hervieu
}

The memory of the barbarians in the garden of the civilised: body and video in the choreographical thinking of Montalvo-Hervieu

Yuji Gushiken ${ }^{1}$ 


\section{Resumo}

O Jardim lo lo Ito Ito, do espanhol José Montalvo e da francesa Dominique Hervieu, constitui-se cenicamente com base em três recursos no processo de criação coreográfica: o virtuosismo presente nas danças populares, a interculturalidade como condição histórica e a tecnologia midiática como intercessora do projeto coreográfico. Em perspectiva interdisciplinar, na interface entre os campos da cultura e da comunicação, o objetivo deste artigo é demostrar e analisar como os coreógrafos, no diálogo com o surrealista alemão Max Ernst, ilustram a tese da dança como pensamento do corpo (Katz, 2005) e sugerem a obra coreográfica como crítica da cultura.

Palavras-Chave: Dança contemporânea memória; corpo; vídeo.

\section{Abstract}

Le Jardin lo lo Ito Ito, by the Spaniard José Montalvo and Frenchwoman Dominique Hervieu, is scenically constituted on three choreographic creative processes: the present virtuosity of popular dance interculturality as a historical condition and media technology as the intercessor of the choreographic project. From an interdisciplinary perspective, in the interface etween the fields of culture and communication, the aim of this article, in the form of an essay, is to demonstrate and analyze how the choreographers, in the dialogue with the German surrealist Max Ernst illustrate the theory of dance as thought of the body (Katz, 2005) and suggest choreographic work as a critique of culture.

Keywords: Contemporary dance; memory; body; video.

ISSN: 1414.5731
O corpo é um guardador de memórias que o tempo inscreve nas profundezas do grande lago que é a consciência. O movimento que um corpo faz já é exercício de recuperação dessa memória em forma de lembranças. Quando o movimento se dá em forma de dança, o que se dá a ver é uma experiência de tempo que o corpo inscreve na produção da espacialidade cênica. Neste caso, dança é experiência presentificada como linguagem que incide na carne bem mais como projeto, tal qual hábito que se instala, do que como obra do acaso. Dança, que impregna o corpo como artifício da cultura, já não pertence ao âmbito do não-pensado, da suposta inspiração que vem linearmente do interior ou exterior. Mas é informação que se dá em trânsito, no vai-e-vem da relação de uma consciência com o mundo. Em resumo, dança como "pensamento do corpo", na proposição teórica de Helena Katz (2005).

A consciência se tece num passeio entre o dentro e o fora em que o corpo insiste em capturar momentos. São esses instantes, perpassados uns nos outros, que criam vocabulários de dança e frases coreográficas. Instantes combinam durações que se dão ao mundo como fluxo recortado entre um antes e um depois. Cada fluxo que se recorta entre as multiplicidades de fluxos possíveis sugere virtualmente uma série potencial de imagens. Movimento que redunda instantes constrói vocabulário. Cria sentido por repetição. Quando a dança se instala como redundância de tempo experimentado é que ela ganha sua forma singular. A contemporaneidade da dança é que ela transita entre aquilo que é e ainda pode vir a ser.

Danç pode ser entendida, assim, como linguagem que se instala no corpo at chegar a um ponto em que, entre a razão e o desejo, trânsito que dispensa engarrafamento de sentidos, já não se sabe mais se o corpo é dono da dança ou se ela é que é dona do corpo. Movimento que se repete, variando em intensidade, é como um dispositivo que se estrutura, e permanece: forças em atrito que provocam sentido, até que este volte a se dissipar. Quando o movimento se estrutura, em forma de vocabulários que se desdobram em frases, é porque o corpo demanda uma repetição que deixa e recupera traços de lembranças na memória.

Se uma dança ganha nome - que pode ser break, flamenco, balé clássico... - é porque um movimento constituiu um território por repetição. Movimento que se repete já é sinal de um desejo que reteve o tempo e o traduziu em vocabulários coreográficos. O movimento a sustentar o corpo sobre e acima do solo já é condição para se transcrever um vocabulário de dança que se desdobra em frases. No corpo que dança há um amálgama de natureza e cultura. Em tal conexão entre corpo processo de significação, o instante que ensaia uma sedimentação no lago da consciência é que produz memória.

\section{Múltiplas memórias na cena coreográfica}

O Jardim lo lo Ito Ito $^{2}$, coreografia do espanhol José Montalvo em colaboração com a francesa Dominique Hervieu, é dessas obras que, alegórica da

2 lo (interieição): Hurra! Grito de triunfo nas festas. Ito: ir muitas vezes. Ver
Dicionário Latino-Português. 
dança como memória produzida, dá-se ao público como colecionadora de experiências de tempo.

Lembro-me da alegria de ver-me fascinado e excitado pelas "fiestas" de outono de minha infância. Havia uma espantosa multidão de participantes coloridos e cosmopolitas. A noite, as pessoas seriam transfiguradas pela dança e pela canção num turbilhão de embriaguez e flerte. Todos tinham seu momento de estrela. Momentos fugazes transformavam a dança em celebração, fantasia selvagem, prazer ilimitado. Momentos de alegria quando o lado sombrio da natureza humana explodia em cor, ritmo, voz, canção, intensa beleza. Esse espetáculo tomou forma a partir do desejo de reconstruir essas emoções de júbilo, palpitação, o jogo de diferenças numa dança, de desafio de todas as formas de xenofobia. Uma alegre ode ao cosmopolitismo $[\ldots] .^{3}$

Neste trabalho coreográfico, de 1999, José Montalvo, espanhol radicado na França, e Dominique Hervieu, coreógrafa associada, ao capturarem lembranças em suas próprias memórias pessoais e na memória dos bailarinos, fazem uma exposição de memórias do mundo. Os dois coreógrafos, com relevantes participações na dança contemporânea na França, criaram a Companhia Montalvo-Hervieu em 1988, recebendo desde então importantes prêmios dedicados às artes cênicas na Europa - entre eles, o Lawrence Olivier Awards (The Society London Theatre, Grã-Bretanha) em 2001, e o Prix SACD (Societé des Auteurs et Compositeurs Dramatiques, França), em 2006. Em O Jardim lo lo Ito Ito, eles colocam em cena bailarinos de distintos grupos étnicos/nacionais e com diferentes formações: danças camaronesa, espanhola chinesa, antilhesa, barroca, break dance, além de balé clássico e técnicas de circo. $O$ Jardim lo lo Ito Ito: paisagem-mundo ou o cosmopolitismo segundo o pensamento coreográfico de Montalvo-Hervieu.

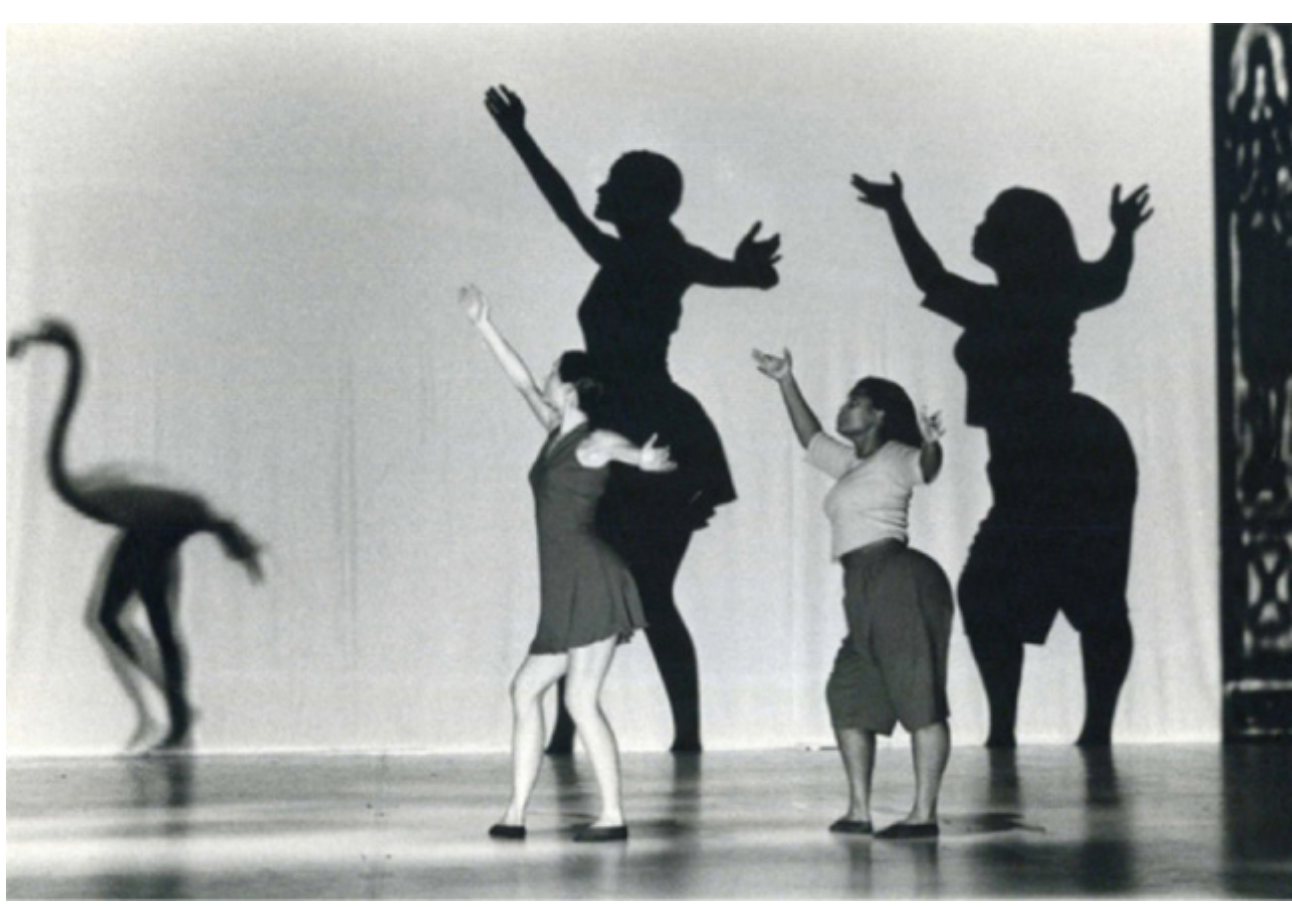

Duos constituídos por monólogos: a diferença questiona a identidade Foto: Laurent Philippe

${ }^{3}$ Texto de apresentaçăa da obra redigido pelo corégrafáo José Montallvo, em
programa exibido no Teatro Municipal do Rio de Janeiro, em 2 e 3 de julho

program 2000 tos vigorosos, típicos do vocabulário coreográfico de uma cultura popular de país constrói um jogo cênico com outra bailarina, que ocupa o palco com vigoroso sapateado espanhol e a sonoridade da castanhola. Suíte dúbia, em que o diálogo visual e sonoro promove muito mais uma difusa afetação mútua entre os dois bailarinos do que um processo de produção de sentidos compartilhados.

Diferentes suítes, com duos formados sempre por dois vocabulários corporais distintos, sucedem-se no palco, que é atravessado por um repertório variado de danças étnicas e populares. As suítes são amostras de tempo experimentado, como memórias do mundo, que se presentificam em vocabulários singulares de dança. Os trechos cênicos constituem-se de sequências não lineares de duos, que se transformam em trios, quartetos ou blocos mais numerosos de bailarinos. A ênase na apresentação de duos, no entanto, privilegia a singularidade de cada vocabulário de dança. Na composição da obra, os duos resultam cenicamente em uma sequência de solos, em que cada solo é o mostruário de uma memória corporal: tempo experimentado no corpo.

Um bailarino executa passos lentos e contidos de uma dança tradicional chifrenéticos. Uma bailarina executa dança caribenha, de matriz africana. Três bailarinos, ao que parece de nacionalidades diferentes, desenvolvem movimentos de break dance. No palco, que ainda recebe outros bailarinos, ocorre um fluxo diversificado de vocabulários de dança que sugerem distintas experiências de tempo nas culturas populares mundo afora. Nestes solos, cada corpo que dança apresenta não só a especificidade dos vocabulários e frases coreográficos produzidos por uma experiência cultural, mas também o virtuosismo performático que cada uma dessas danças demanda de um corpo.

Cada bailarino, como coproprietário dessa coleção de tempos, torna-se, assim um gestor desse imaginário cosmopolita, na medida em que faz de sua dança um investimento na constituição subjetiva do projeto coreográfico. Em O Jardim lo lo Ito Ito, cada corpo apresenta aquele repertório desenvolvido ao longo do tempo como experiência de uma tradição cultural. O que se vê em cena são suítes em que distintos vabulários de dança, ao insinuar o início de um diálogo, promovem não mais que intersecções ínfimas entre códigos diversos, de modo que os virtuais sentidos apenas esboçam produzir um lugar comum. Com base neste princípio da fala sem audição, não há hegemonia de um código sobre outro.

Os diálogos entre bailarinos, em profusão babélica, tornam-se monólogos simultâneos: a relação entre dois códigos distintos não produz uma terceira e nova dança que resulte de uma síntese das duas primeiras. Na manutenção de singularidades coreográficas, em que se tece uma multiplicidade de códigos, é que estaria a romessa de uma imaginada dinâmica cultural. O que entra em cena é o mais franco processo de afirmação de singularidades. Sem estrutura hierárquica para ditar a maior ou menor "nobreza" de vocabulários de dança, é através desta composição aberta e heterogênea que a dupla de coreógrafos vai fazer a "alegre ode ao cosmopolitismo". 
Flamenco ou dança chinesa, break dance ou dança camaronesa: em O Jardim o lo Ito Ito, cada dança se dá a ver, em uma tal velocidade dos monólogos, na base de um "automatismo psíquico". Esse recurso produtor de linguagem, formalmente usado como experimentação poética no movimento surrealista, buscava explorar, na obscuridade do inconsciente, um novo imaginário para se refazer a realidade produzida e percebida em estado de consciência. A prática do automatismo psíquico buscava ampliar consideravelmente o campo do "arbitrário imediato", como lembrava André Breton (2001)

O arbitrário imediato, na potência de fazer emergir uma imagem qualquer, torna-se o indício de que, pelo menos como memória produzida, a dança que se dá a ver na brusca aparição de tal automatismo, estava incrustada no corpo que dança não só como armazém do inconsciente. Mas, na coexistência virtual de presente e passado na memória (Bergson,1999; Deleuze,1999), estava também como lei que, em tese, só se produziria numa outra arbitrariedade do pensamento racional e selecionador. $E$ eis aqui o trânsito de faculdades que faz do corpo um dispositivo onde distintas forças se cruzam, em diferentes direções, até que num dado instante produzem um "agora" que permanece na memória. Essa memória permanece em sua potência virtual, até ser recapturada e emergir em forma de lembranças no corpo que dança.

A instantaneidade da dança que se atualiza no corpo, de forma abrupta e veloz endossa a perspectiva de que ela já estava incorporada como memória, como le (Katz, 2005) e, portanto, como tempo arbitrariamente repetido até formar vocabulários de dança e frases coreográficas. Um vocabulário de dança se singulariza porque se repete, produzindo diferença em relação a um outro vocabulário. E eis aqui um paradoxo, no qual lei e acaso não são fundamentos antagônicos, mas elementos de um dispositivo que se dirigem a várias direções e que, num dado momento, firmamse numa estrutura que designa uma tipologia em dança.

\section{Poética da justaposição a serviço do movimento}

O Jardim lo lo Ito Ito, no dizer do próprio José Montalvo, produz as condições para que haja uma poética da justaposição e do desvio a serviço do movimento, do desejo, do fantasma, do sonho, da infância. ${ }^{4}$ Desenvolve-se um pensamento coreográfico que privilegia processos cognitivos e vocabulários de dança produzidos por distintos povos em espaços e tempos diferentes. É a partir destas apostas na produção da diferença que surgem as epifanias do corpo e de seu inconsciente.

A tese da dança como pensamento $(K a t z, 2005)$ se aproxima da tese da memória como ação que prolonga imagens do passado no presente (Bergson, 1999), na medida que o projeto coreográfico dialoga com singularidades culturais e as atualiza na produção do espaço cênico. O que há de contemporâneo em $O$ Jardim lo lo Ito to é o fato de memórias das culturas populares, consideradas como epistemes ou saberes, atualizarem-se como elementos constituintes do pensamento coreográfico.
O break, por exemplo, tem seu próprio vocabulário, suas próprias imagens. Nessa dança de rua, em que é forte a relação do corpo do bailarino com o solo, o movimento pode começar tanto nas extremidades - pernas e braços - quanto no torso. Aparentemente mais estático nas frases de break, o torso funciona como ponto de articulação que permite o fluxo dos movimentos que atraem a atenção do espectador principalmente para as extremidades do corpo. Assim, o break constitui seu próprio vocabulário e frases coreográficas, exigindo, para se dar a ver como dança, um corpo disciplinado e que se desdobra em processos de repetição de movimentos. Já ascese do treinamento e a diversão da dança popular urbana, o disciplinamento do corpo para gerir esse dispositivo é que demanda uma noção de virtuosismo que não se decalca para outra dança que não o break. Questão de singularidade que passa cessariamente pela afirmação de uma escrita corporal como processo de criação.

Uma dança que se inscreve como uma tipologia de movimento tem lá suas próprias arbitrariedades - e cada arbitrariedade que se constrói é como aquilo que em antropologia se chama de tradição, ou seja, um modo de produção de linguagem que, servindo como desvio de um parâmetro, se estabelece como outro parâmetro. Em outros termos, uma antiga hipótese no campo da cultura, mas um tema ainda 
insistente no mundo contemporâneo: o eu não existe sem o outro, que é uma condição de produção de diferença (Silva; Hall; Woodward, 2000). Em O Jardim lo lo Ito Ito, não se trata de dirigir corpos para que absorvam linguagens codificadas, seja a do balé clássico, essa ainda grande matriz disciplinar no repertório mundial de dança, ou de outras variações de dança moderna ou contemporânea. Não se trata sequer de um corpo apreender a produção de linguagem que outros corpos apresentam na sequência dos solos. Trata-se, isto sim, de aproveitar, na composição da obra, uma estrutura cognitiva e motora que cada bailarino já detém como memória.

Em cena, danças de referências étnicas e populares afirmam-se como singularidades constituintes de uma paisagem mundializada. Movimento que retém o tempo é porque já começa a fazer sentido. Memória contém o sentido que permanece, manifesto ou latente, na produção e no uso da linguagem. Se assim é, trata-se de perceber que o movimento se processa como lembrança capturada no fundo da memória e traduzida como dança-pensamento. $O$ Jardim lo lo Ito Ito, ao afirmar singularidades de memórias em forma de movimento, dá-se a ver como dança-dissertação sobre as tensas relações interculturais que constituem a União Européia. O panode-fundo sociopolítico refere-se não apenas à quebra de fronteiras entre as nações do bloco econômico, mas também ao fluxo criminalizado de imigrantes oriundos de além-bloco e de além-continente, numa Europa em estado de atualização.

Para Michael Hardt, na leitura que faz do filósofo Henri Bergson, atualização é uma passagem da virtualidade ao ato, sendo propriamente um ato criativo, o que acontece somente no que Bergson chama de "duração" (Hardt, 1996, p. 49). Gilles Deleuze, que produz um diálogo intenso com a obra de Henri Bergson, já endossava também a perspectiva bergsoniana, segundo a qual, duração, como experiência de tempo, é essencialmente multiplicidade (Deleuze, 1999, p. 63).

Em um longo processo de atualização como este a que se chama de continente europeu pode-se perceber o paradoxo virtual do tempo como multiplicidade. $\mathrm{Na}$ mitologia grega, Europa é o nome de uma princesa nascida no Leste, mas que, dada a sua vida trágica, é levada por Zeus a viver em Creta, isto é, no Oeste. Por conta de uma princesa que migra forçadamente nessa narrativa mítica, a região de Creta, da Grécia e todo o continente passou a se chamar Europa (Gandon, 2000, p. 108). Ou seja, antes de se tornar uma entidade política, o continente europeu já trazia, em sua fabulação mítica, um quê de Oriente. Desde seus princípios, antes mesmo de delimitar suas fronteiras geográficas e imaginárias, o continente europeu já vinha se constituindo com um trânsito entre um "dentro" e um "fora".

A Europa, que se dá forma como entidade política a partir do século XVIII, cria a deia simultânea de cultura ocidental e de cultura moderna. Dá-se uma imagem, inventa suas próprias mitologias e vai se autorreferenciar como a mais elevada cultura já registrada em todos os tempos (Heller; Fehér, 1998, p. 214). Ela só se permite existir como projeto político tendo, ainda como parâmetro, tudo aquilo que era não-Europa, não civilizado. No entanto, aquilo que se designa de "cultura européia", no fundo, é ela própria uma multiplicidade de culturas: inglesa ou alemã, francesa ou italiana, e cada qual com as singularidades que as constituem enquanto identidades nacionais. O que não está sob o guarda-chuva de suas contingências socioculturais e de suas fronteiras físicas e imaginárias ganha um rótulo: os "Outros" enquanto "bárbaros".

Como dissertação sobre o mundo, em especial sobre os desafios do cosmopolitismo, O Jardim lo lo Ito Ito coloca em cena e em pauta um tema caro às sempre atuais preocupações relativas à convivência e à tolerância entre indivíduos de distintos padrões culturais: até que ponto é possível a convivência dos diferentes se o que se afirma, nos dias de hoje, é já nem tanto o projeto moderno da igualdade, mas a afirmação da própria diferença?

\section{Vídeo: demanda de corpos e a identidade convulsiva}

A tensão entre identidade e diferença, ou a representação da alteridade como monstruosidade (Sodré, 1996, p. 171), ganha em complexidade e atualidade quando os coreógrafos colocam em cena projeções de vídeo, nas quais seres de corpos híbridos de humanos e outras espécies animais "dançam" em companhia dos bailarinos de carne e osso que se movem pelo palco. Em dado momento, a figura de uma muher com corpo de peixe-dourado transfigura-se na mídia digital e constitui a cena coreográfica. Em seguida, um torso humano instalado num corpo de tigre também constitui a cena. Um torso humano feminino, contíguo a um corpo equino, integra esta demanda de corpos no projeto coreográfico. A recriação de corpos fabulosos prossegue na cena de um flamingo, ave de plumagem em tons rosa e vermelho, com pernas humanas.

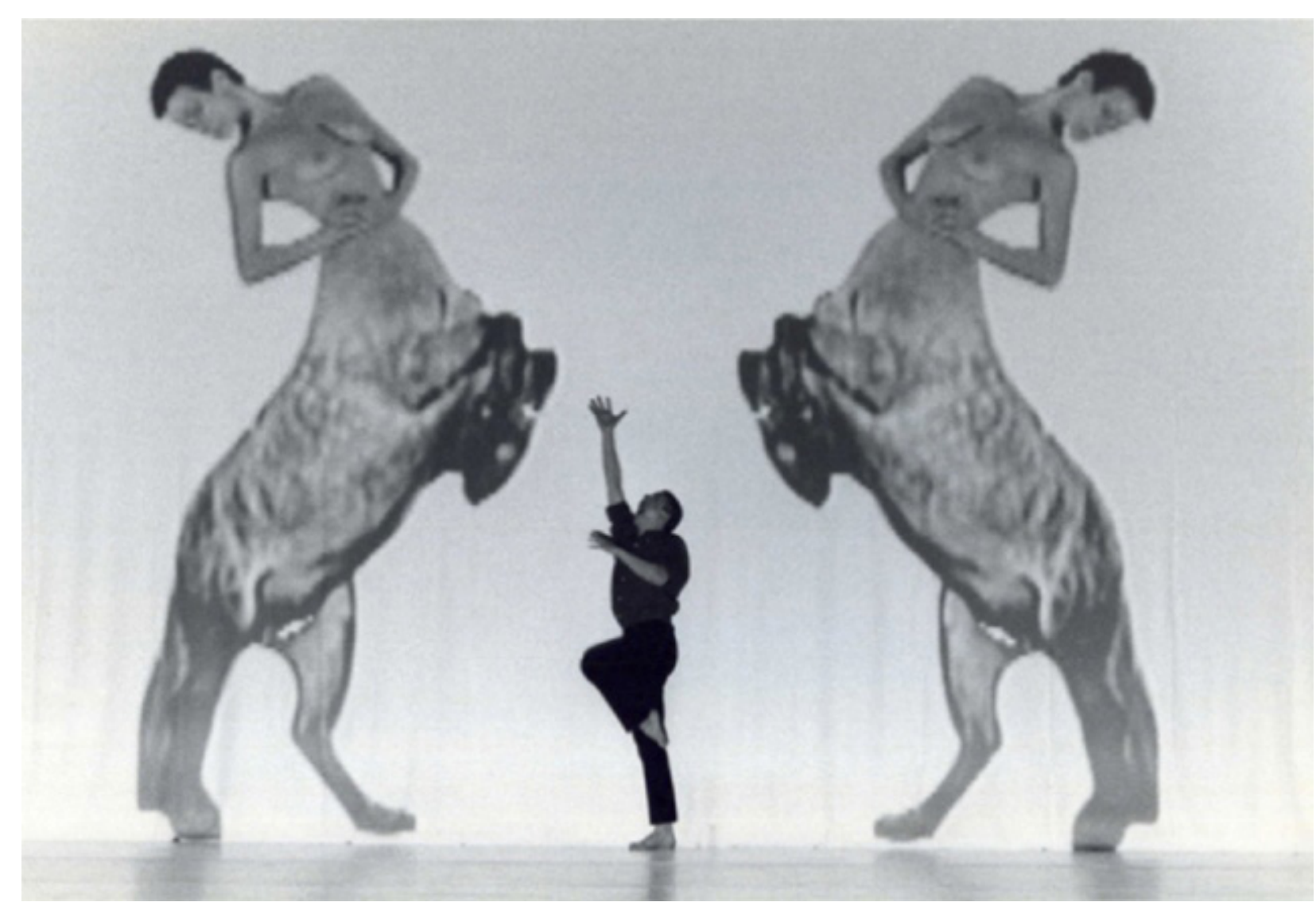

Corpos hibridos: video e colagem na releitura do surrealismo de Max Ernst. Foto: Laurent Philippe

A hibridação de seres humanos com outras espécies animais tende a ser do âmbito do biologicamente incompatível. No entanto, essas são combinações atu- 
alizáveis em processos de produção do desejo e de imaginação na criação coreográfica. Arte é que também esgarça o processo lógico de discursos, como o científico, abrindo caminho para a faculdade da imaginação. Nessa recriação do imaginário de corpos, em que se faz um exercício de fabulação, recriam-se as condições de pensamento para que haja dança.

Mas essas zonas de intersecções entre corpos de naturezas distintas são indícios também de uma mistura que, se desejável no plano da imaginação, em especial na imaginação coreográfica, nem sempre é possível na concretude da realidade cotidiana de etnias, nacionalidades e outras formações identitárias ${ }^{5}$. absurdo dos corpos fabulosos atualiza uma hibridação não no nível tipológico mas no topológico, em que a estrutura do corpo - portanto, da identidade - fica profundamente alterada.

A identidade profundamente alterada, instantânea e convulsiva era uma constante nas imagens surrealistas do alemão Max Ernst (1891-1976), cujos trabalhos na fase de colagem - mistura, por assim dizer - ganham a tradução em vídeo na montagem de $O$ Jardim lo lo Ito Ito. Nessa obra coreográfica, os personagens híbridos produzidos em vídeo são referências aos trabalhos de colagem, entre outras técnicas criativas, de Max Ernst.

O princípio da colagem, segundo Ernst, era a reunião de dois planos dissociados. A dissociação entre planos constitui um vácuo tal qual imagens oníricas justapostas que, na folia do inconsciente, não se ligam umas às outras através de nexos. De certo modo, tal princípio de justaposição de imagens se aplicava à noção de identidade pessoal. No caso, identidade como bricolagem de muitos eus, uma composição de muitos planos dissociados. A consciência do indivíduo, dizia o surrealista alemão, era um espaço de cruzamento, de confrontação, que era, por sua vez, o espaço da "beleza convulsiva" e da "identidade convulsiva" (Gimferrer, 1983).

Max Ernst, leitor de Sigmund Freud, foi buscar a formação desse outro imaginário intempestivo no que o criador da psicanálise chamou, a princípio, de in consciente. Nos sonhos, onde proliferam imagens insistentemente desprovidas de conexões lógicas, já estavam criadas as condições para que se ensaiasse - nas artes plásticas, na política, na dança, no que quer que fosse - uma dissolução da identidade até então fomentada em estado de vigília. No estado de consciência vigia-se a dinâmica inconsciente de onde podem se originar os mais perigosos delírios e as mais fantásticas imagens oníricas. Suspender a razão, sem necessariamente revogá-la, eis aí por conta de Max Ernst, como que pegando carona artística no inconsciente segundo Freud, um modo de fazer ver que o movimento - a dinâmica - também é algo próprio da identidade.

O corpo demandado pela imaginação coreográfica já não é mais necessariamente do âmbito apenas da condição biológica. O corpo que dança, portanto, nem sempre se encontra no âmbito de uma tipologia da natureza. Em processo de étá na imaginação, processando-se mais como algo fabulado do que como atualidade já produzida em carne, ossos e nervos.

O que se vê em O Jardim lo lo Ito Ito são condições virtuais de haver corpo e, portanto, de haver dança: um corpo biológico em seu devir tecnológico. No vídeo, tecnologia veiculadora de imagens e produtora de imaginário, os corpos passam por metamorfoses para ilustrar a imaginação como aquela faculdade em que o desejo (quase) tudo pode processar, distorcendo e refazendo o que se entende por realidade. Seria como dizer que a hibridação-bricolagem de corpos é atualizável em sua potência virtual. Para além da concretude do palco, a simulação do corpo na tecnologia do audiovisual é que permite que a dança se instale - já nem tanto na carne, mas nos circuitos eletrônicos e digitais dos artefatos midiáticos.

Corpo que faz mediação da dança como fluxo é o mesmo corpo que se permediar pela tecnologia - indícios de que a dança se atualiza na medida em que faz links para habitar outros espaços produzidos pela imaginação. Essa metamorfose que produz um novo imaginário, via artefato tecnológico, faz emergir uma outra identidade - uma recriação das tensões entre natureza e artefatos tecnicos, constantes da obra de Max Ernst. Esta é a ideia do "corpo saindo de si mesmo", "adquirindo novas velocidades" e "conquistando novos espaços", na virtualidade de que fala Pierre Lévy (1996).

O corpo que dança, portanto, enfatiza sua atualidade como um corpo artificialmente monstruoso pela mediação tecnológica, na medida em que essa mediação torna-se elemento potencializador do corpo como alteridade de si mesmo e que, nessa condição fabulosa, vai constituir o projeto coreográfico de Montalvo \& Hervieu. O interesse atual pelo monstro como alteridade que se apresenta - e que incide no pensamento em dança contemporânea - se dá porque "talvez precisemos das suas figuras para recolocar a pergunta sobre a humanidade do homem, esgarçadas as certezas da sua identidade e a inteireza neste mundo onde fazermos proliferar as associações entre a carne e o metal (Tucherman, 1999, p. 99)

No palco de $O$ Jardim lo Ito Ito Ito, as danças que diferentes corpos - aqueles ainda biológicos: de carne, ossos e nervos - processam não se contaminam mantendo a singularidade de cada uma delas. Esta não-contaminação contradiz hibridação de corpos no vídeo, sugerindo talvez que as hibridações culturais são potencialidades do virtual (oposto do atual), mas não são, necessariamente, ma demanda. A afirmação de singularidades identitárias nos dias de hoje sus cita pelo menos duas questões: uma se refere à produção de subjetividade que incita a produção da diferença e outra que, com base no discurso dos direitos fundamentais, produz uma crítica ao viés fascista incrustado mesmo nos movimentos minoritários.

\section{Considerações finais}

O palco em O Jardim lo lo Ito Ito é um espaço aberto em sua potência virtual. Ali, não se pede licença para dançar. Simplesmente se dança o que se sabe. 
Assim como nas "fiestas" espanholas, todo mundo, cada qual em sua singularidade, tem sua "hora de estrela", como dizia José Montalvo na apresentação da obra. Na construção coreográfica de $O$ Jardim lo lo Ito Ito, o que tem demarcação é cada movimento, que se constrói, cria vocabulário e ganha nome. Nomear já é uma forma de demarcar um território. Uma dança ganha uma designação um nome, colocando cerca nas variações do movimento.

Em O Jardim lo lo Ito Ito, o que há são movimentos que se tornam marcadores de uma experiência de tempo: o tempo repetido pelas invenções de vocabulários de dança no âmbito das culturas populares. Pelo projeto de composição por justaposição, não há centro nem periferia nessa obra coreográfica, nem personagens principais nem figurantes. Cada vocabulário de dança colocado em cena apresenta um movimento que ganhou nome e designa uma singularidade qualquer. Mas, plenas de identidades, as danças apenas transitam pelo palco. Não permanecem. Princípio de nomadismo que caracteriza o espaço como multiplicidade (Deleuze; Guattari, 1997, p. 192).

A obra coreográfica torna-se uma totalidade aberta porque o palco onde a dança se dá a ver aponta para um espaço não transformado em lugar. A intensidade do trânsito faz poeira sobre a pólis grega e a vila romana. Toda dança é bárbara no Jardim lo lo Ito Ito. Nesse processo de criação coreográfica, as identidades, ainda que em estruturação, ao mesmo tempo se desvanecem, como imaginava Max Ernst (Gimferrer, 1983). Esse desvanecimento não significa retirar as tipologias das nacionalidades e dos grupos étnicos, e nem indiferenciá-las sob o guarda-chuva de uma suposta cultura global e transnacional, cujo centro seria a Europa, herdeira direta da civilização grega e suas influências sobre o mundo ocidental.

Pelo contrário, trata-se de uma afirmação de identidades através da disputa pela constituição de imagens no espaço cênico, que é simultaneamente ocupado e desocupado pelas diferenças que o atravessam. Condição incômoda, porque fluida, de uma Europa cuja formação na contemporaneidade parece se aproximar, ela própria, muito mais de um dispositivo migrante-nômade do que de uma estrutura permanente e com identidade estável. Europa: território que pode ser um pedaço do mundo ou o mundo inteiro, como ponto de passagem em que o espaço é ao mesmo tempo permanência e fluxo, e os seus personagens, sedentários, migrantes e nômades.

Cada vocabulário de dança que atravessa o palco desse Jardim é uma linha de força limitada por outras linhas de força. O que há é multiplicidade, que se esgarça ainda mais com a tecnologia do vídeo na medida em que rearranja novas condições de fabulação corporal. E o que paira no ar já não são apenas corpos que dançam, mas também o desconforto de se pressentir que identidade produz não só diferença, mas produz - também - indiferença. Danças que não se contaminam são alegóricas da afirmação da singularidade e da preservação da memória inscrita como experiência de tempos, no plural. Tempos que coexistem e constituem o espaço cênico.

Espaço, para se tornar lugar comum, demanda a coexistência de experiências de tempo. Quando produz identidade, um espaço torna-se necessariamente justaposição de tempos que coabitam. E que, em intensidades diversas, fazem repelem. Cada singularidade encontra um porto seguro no tempo que retém isso da imai位o do tempo um tempo específico e produzindo memórias que se guardam no corpo. Para bem além desse conforto proporcionado pela identidade, é na sua relação com a exterioridade do mundo que uma consciência percebe que o lado de fora do corpo tem também vocação para produzir desconforto.

No entanto, esse desconforto da exterioridade também oferece potencialidades de relações interculturais que fazem diferença no trajeto, que sempre se deseja linear, de cada identidade. É desse desconforto com a exterioridade que se cria O Jardim lo lo Ito Ito. Nesta dança-mundo, as singularidades que constituem cada narrativa do projeto coreográfico são um pretexto para se falar das tensões entre xenofobia e cosmopolitismo. Dança: pensamento do corpo, projeto de subjetivação e modo de se fazer a crítica da cultura no mundo contemporâneo.

\section{Referências}

BERGSON, Henri. Matéria e Memória: Ensaio sobre a Relação do Corpo com o Espírito. Trad. Paulo Neves. São Paulo: Martins Fontes, 1999.

BRETON, André. Manifestos do Surrealismo. Rio de Janeiro: Nau Editora, 2001

COMPAGNIE MONTALVO-HERVIEU, criada em 1988. Disponível em: <http://www.montalvo-hervieu.com>. Acesso em 25 jun. 2012.

CRETELA JR., José; ULHÔA, Geraldo (org.). Dicionário Latino-Português. São Paulo: Companhia Editora Nacional, 1956.

DELEUZE, Gilles. Bergsonismo. Trad. Luiz B. L. Orlandi. São Paulo: Editora 34, 1999

DELEUZE, Gilles; GUATTARI, Félix. Mil Platôs: Capitalismo e Esquizofrenia. Vol. 5. Trad. Peter Pál Pelbart e Janice Caiafa. São Paulo: Editora 34, 1997.

GANDON, Odile. Deuses e Heróis da Mitologia Grega e Latina. São Paulo: Martins Fontes, 2000

GIMFERRER, Pere. Max Ernst. Trad. Francisco de Castro Azevedo. Rio de Janeiro: Ao Livro Técnico S/A, 1983.

HARDT, Michael. Gilles Deleuze: um Aprendizado em Filosofia. Trad. Sueli Cavendish. São Paulo: Editora 34, 1996

HELLER, Agnes; FEHÉR, Ferenc. A Condição Política Pós-Moderna. Trad. Marcos Santarrita. Rio de Janeiro: Civilização Brasileira, 1998. 
KATZ, Helena. 1, 2, 3. A Dança é o Pensamento do Corpo. Belo Horizonte: FID Editorial, 2005.

LÉVY, Pierre. O que é o virtual? Trad. Paulo Neves. São Paulo: Editora 34, 1996.

SILVA, Tadeu Tomaz; HALL, Stuart; WOODWARD, Kathryn. Identidade e Diferença: a Perspectiva dos Estudos Culturais. Petrópolis: Vozes, 2000.

SODRÉ, Muniz. Reinventando a Cultura: a Comunicação e seus Produtos. Petrópolis: Vozes, 1996.

TUCHERMAN, leda. Breve História do Corpo e de seus Monstros. Lisboa: Editora Vega, 1999.

Recebido em 07/03/2014

Aprovado em 02/07/2014 